\title{
Integrated (one-stop shop) youth health care: best available evidence and future directions
}

\author{
Sarah E Hetrick', Alan P Bailey', Kirsten E Smith², Ashok Malla³, Steve Mathias' ${ }^{4}$, Swaran P Singh ${ }^{5}$, Aileen O'Reilly ${ }^{6}$, \\ Swapna K Verma ${ }^{7}$, Laelia Benoit ${ }^{8}$, Theresa M Fleming ${ }^{9}$, Marie Rose Moro ${ }^{8}$, Debra J Rickwood ${ }^{10}$, Joseph Duffy ${ }^{6}$, \\ Trissel Eriksen", Robert Illback², Caroline A Fisher'³, Patrick D McGorry'
}

M ental health problems represent the largest burden of disease in young people. ${ }^{1}$ Fifty per cent of mental disorders first emerge by the age of 14 years, and $75 \%$ by the age of 24 years. ${ }^{2}$ Left untreated, these mental health problems have high rates of recurrence and cause negative outcomes for the individual, including reduced economic productivity, as well as societal costs. ${ }^{3-6} \mathrm{~A}$ range of risk behaviours coexist with mental health difficulties, including tobacco, drug and alcohol use; sexual risk taking; injury-related risk behaviour; violence; reduced levels of physical activity; and poor nutrition..$^{7-9}$ Health behaviours laid down during adolescence and young adulthood tend to continue long term. ${ }^{8,9}$

Despite this, access to mental health services for young people has been poor. ${ }^{10-13}$ Identified barriers to help-seeking for young people include internal factors, such as concerns about confidentiality, lack of knowledge about mental health disorders and available services and perceived attitudes of clinicians; and external barriers, including lack of access and financial costs. ${ }^{79}$ Historically, mental health services have not been developmentally sensitive or youth-oriented. Many services restrict access depending on age, diagnosis or comorbidities. Further, poor engagement of young people in child and adult psychiatric services has been endemic, and challenges in transitioning young people between and across these services has often been poorly dealt with. ${ }^{14-16}$ Together, these processes have caused a "crisis in care", where most young people with mental health difficulties do not get the care they need, resulting in high rates of distress, functional impairment and suicidality. ${ }^{17-19}$

\section{Integrated youth health care}

Internationally, integrated care has been proposed as a solution to this crisis. Integrated care has been described in terms of an integrated practice unit with both clinical and non-clinical personnel providing multidisciplinary care, ideally in one location,$^{20}$ in line with evidence that shows young people may prefer to have all their needs met in one place. ${ }^{21}$ Integrated care joins up primary mental and physical health care services with social care, so that services are organised and coordinated around the needs of the individual. ${ }^{20,22-24} \mathrm{~A}$ recent systematic review found improved mental health outcomes for young people who received integrated care compared with usual care. ${ }^{25}$

There is general agreement about requiring cooperation and collaboration of services around the needs of the

\section{Summary}

- Although mental health problems represent the largest burden of disease in young people, access to mental health care has been poor for this group. Integrated youth health care services have been proposed as an innovative solution.

- Integrated care joins up physical health, mental health and social care services, ideally in one location, so that a young person receives holistic care in a coordinated way. It can be implemented in a range of ways.

- A review of the available literature identified a range of studies reporting the results of evaluation research into integrated care services.

- The best available data indicate that many young people who may not otherwise have sought help are accessing these mental health services, and there are promising outcomes for most in terms of symptomatic and functional recovery.

- Where evaluated, young people report having benefited from and being highly satisfied with these services.

- Some young people, such as those with more severe presenting symptoms and those who received fewer treatment sessions, have failed to benefit, indicating a need for further integration with more specialist care.

- Efforts are underway to articulate the standards and core features to which integrated care services should adhere, as well as to further evaluate outcomes. This will guide the ongoing development of best practice models of service delivery.

individual, ${ }^{20,26,27}$ but integrated care can be achieved through various models of service delivery. ${ }^{28,29}$ These models have arisen out of diverse philosophical, cultural, fiscal and political contexts internationally. Although co-location is the ideal, it does not necessarily ensure coordinated care, as co-location can simply mean that different services are housed under one roof but continue to operate in a siloed manner. ${ }^{28,29}$ Integration can happen at different levels and through different mechanisms and exists on a continuum from formalised agreements and arrangements between services, through services using the same referral and assessment processes or sharing administrative processes, medical records and team meetings, to collaborative care approaches and dedicated multidisciplinary onsite teams with a common culture of care. . $6,30,31$

Primary care (also called Tier 1 in the United Kingdom and United States ${ }^{32}$ ) is the first point of contact for people in the

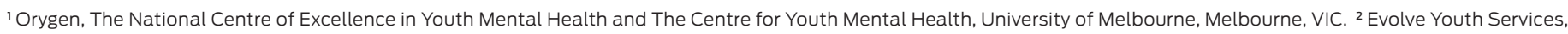

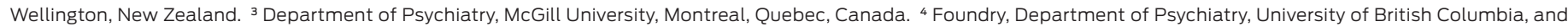

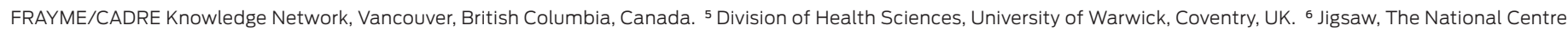

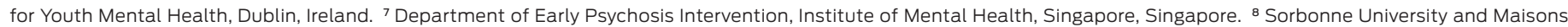

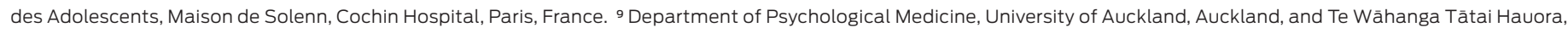

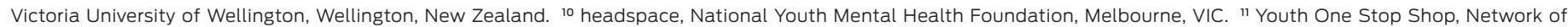

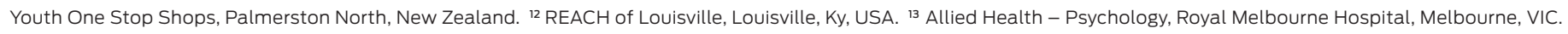
\@ pat.mcgorry@orygen.org.au·doi: 10.5694/mjal7.00694
} 
health care system; it has the widest scope and is characterised by continuity of care. Secondary care (Tier 2) involves treatment of more complex illnesses and conditions, and tertiary care (Tier 3 ) is highly specialised care. ${ }^{32}$ Accessing mental health services through the less stigmatised and more visible and familiar primary health care services ${ }^{33-36}$ - such as through general practice in Australia and primary paediatric services in the US - where the focus has traditionally been on physical health concerns, has typically been the approach taken by decision makers keen to improve access to mental health care for young people. ${ }^{24}$ However, it has been acknowledged that young people may be reluctant to access traditional primary health care for mental health difficulties, ${ }^{37}$ highlighting the importance of a youth-friendly approach that is matched to the needs of the young person. Research has shown that young people respond better to services that are youth-specific rather than add-ons to child or adult services. ${ }^{38}$

Despite the diversity in terminology and the various models of service delivery, principles for integrated care are identified in the World Health Organization framework for adolescent and young adult-friendly services. ${ }^{39,40}$ Although relevant to health care consumers of any age, these principles specifically address issues of poor access in youth by stipulating that services should be accessible, acceptable, appropriate, effective and equitable. These principles have been developed into the following key characteristics of integrated care services. ${ }^{7,31,37,41}$

- Services should take a developmental and youth-centred approach to providing comprehensive and integrated care that is holistic, addressing multiple issues in a seamless way and not limiting entry according to a narrow set of criteria, including ensuring flexible tenure and re-entry into care if needed.

- Services should be accessible in terms of location (centralised and easy to reach), hours of operation and cost (free) and should offer multiple entry points, including provision for self-referral and drop-in services. They should provide a timely response to all young people regardless of factors such as age (catering for a wide age range), severity of presenting problem, ethnicity or religion.

- The environment should be safe and youth-friendly by being, for example, informal, not visibly clinical and nonstigmatising. Often a highly visible and youth-friendly "shop front" or "youth café" ambience and design (such as a single entry point with youth-friendly, non-clinical, nonstigmatising branding and environment) is advocated.

- Services may also provide recreational or arts activities and drop-in or hang-out space.

- Services should be integrated in the community, and the community should be made aware of the service.

- Services should be confidential and ensure privacy.

- Services should be evidence-based.

- Staff should be welcoming, respectful, experienced and skilled in working with young people. They should provide information and take an approach that allows informed and free choice (shared decision making ${ }^{42}$ ) about care.

- Youth (and family) participation is advocated for the planning, delivery and evaluation of services. ${ }^{7,20,31,43}$

- Ongoing evaluation of services is recommended. ${ }^{7,31,43,44}$
In response to this growing advocacy for integrated youth mental health services, several initiatives have been developed internationally. Some of these have been mutually collaborative or sequential in nature. In this review, we describe the existing services, including the type of care they provide, and to whom, and document the nature of evaluation that has been undertaken and what this shows with regard to mental health outcomes. We include studies and evaluation reports about services for young people (aged 10-30 years) that include a mental health function and are integrated - in that they bring together or provide a range of physical health, mental health and social service foci - typically involving co-location of services or processes that allow easy access to relevant services. We focus on characteristics of service delivery (eg, accessibility, youth participation), as well as who is accessing these services, their symptomatic and functional outcomes, and satisfaction outcomes relevant to service provision (access, satisfaction, outcomes of intervention).

We have not included descriptions of: school-based services; services where the focus is on sexual and reproductive health, AIDS or other specific physical health issues; traditional child and adolescent mental health tertiary services, where coordinated care may take place via a case manager; or wraparound services, where service providers agree to work together for specific individuals but are not co-located or integrated in an ongoing way.

\section{Literature review methods}

Our literature review included three key strategies for searching, supplemented by ancestry searching, wherein we examined the reference lists of relevant studies.

First, we searched for academic peer-reviewed literature through comprehensive database searches of PsycINFO, MEDLINE and EMBASE that included articles published in any language from the earliest available date to 20 February 2017. We used search terms reflecting the target population (eg, youth, adolescent, young adult), services (eg, mental health, health care) and service descriptors (eg, integrated, community-based, youth-friendly).

Second, we used the US, Australian, New Zealand and UK Google platforms (google.com, google.com.au, google.co.nz and google.co.uk) to search for grey literature that was not published academically. ${ }^{45}$ After an iterative process to determine which search terms were the most appropriate and produced the most relevant results, the search phrases "youth one stop shop evaluation" and "youth friendly integrated mental health services evaluation" were used. We used only the first 20 search results on each Google site to ensure that only relevant literature was included in the review (sensitivity was $80 \%$ using 20 records and $57 \%$ using 30 records). We also searched other pages linked from the websites obtained from the Google search for relevant information. However, links to new websites that were not uncovered by the search were not followed.

Third, international experts in the field, in New Zealand, Canada, the UK, US, Ireland, Singapore and France, for whom we could obtain contact details, were contacted by email. These experts were people involved in advocacy for, and organisation of, these types of services, as well as those in leadership positions in the services. This expert panel provided reports that we were unable to access in journals or through our Google searches and they assisted with providing data where these were missing from a report. As the expert panel was assembled on the basis of their 
roles in services relevant to this review, they may be considered to have competing interests; however, the expert panel had no role in interpreting or synthesising the data for this review.

\section{Service characteristics}

We located 49 relevant documents describing 45 evaluations, including two planned or ongoing evaluations, of 18 different services or networks of services (where more than one service existed under the same name or branding). Three of these studies, about a network of services in New Zealand, were located through ancestry searching.

Multiple evaluations have been undertaken for some of the larger networks, which may have used overlapping samples, studied a single service within the network or used large datasets to evaluate the entire network of services. As we included evaluation reports describing outcomes from both large datasets across a whole network of services and datasets drawn from individual services (some of which were within a network), in some cases the data from individual sites may have also been included in the larger datasets for the associated network.

\section{Location of services}

The characteristics of the 18 services or service networks described in the 45 completed and ongoing evaluations are fully described in the Box. ${ }^{46-93}$

We identified six networks of services with relevant data:

- Jigsaw in Ireland - 10 services in 2014, now 13 services;

- headspace in Australia - 67 services in 2014, now 103, with another seven due to open in 2017;

- Maisons des Adolescents in France - 104 centres;

- Youth One Stop Shops (YOSS) in New Zealand - 11 services funded as part of the YOSS network;

- Foundry in Canada - seven centres, with four planned to open in 2018; and

- Irish YOSS - four services.

We identified two additional networks with evaluations in progress: a pan-Canadian network called ACCESS Open Minds (ACCESS OM), for which a large-scale pre-post evaluation is underway; ${ }^{93}$ and a smaller network in Canada, the Integrated Collaborative Care Team (ICCT) services, for which a randomised controlled trial is underway. ${ }^{46}$

We also located evaluations of 10 single services:

- Your Choice in New Zealand;

- Community Health Assessment Team (CHAT) in Singapore;

- The Well Centre, Youthspace and The Junction in the UK;

- Supporting Positive Opportunities with Teens (SPOT) in the US;

- Adolescent Health Service in Israel; and

- Rural Clinic for Young People, YStop (Youth Stop) and the KYDS Youth Development Service in Australia.

Most services or service networks have been established since 2000, with the exception of New Zealand's YOSS (established in 1994) and the Adolescent Health Service in Israel (1993).

\section{Target population and focus}

Four of these 18 services or service networks (The Junction, Adolescent Health Service, Rural Clinic for Young People and KYDS Youth Development Service) $)^{56,64,65,67}$ catered for adolescents up to the age of 18 years, and one (The Well Centre ${ }^{52}$ ) up to the age of 20 years, with most providing services for people up to the age of 24 or 25 years (or 30 years in the case of $\mathrm{CHAT}^{62}$ ) (Box). Most services had a lower age limit of 11 to 14 years, but the services in New Zealand included children aged 10 years. ${ }^{57-61}$

While all services included mental health service provision as well as other service foci, four services or service networks (Jigsaw, Youthspace, The Junction and CHAT) were described as having mental health as both their target issue and primary focus. Six (Irish YOSS, New Zealand YOSS, headspace, Foundry, Maisons des Adolescents and ACCESS OM) described the target issues and services as being inclusive of mental health, alcohol and drug problems, physical health and vocational and educational problems. The remainder had a combination of several of these foci. At least one service network (New Zealand YOSS) highlighted that, although it includes a mental health service function, it is not explicitly a mental health service. ${ }^{59}$

Within the networks of services in Ireland, Australia and New Zealand, the target population and services offered varied between the services within the networks. Twelve of the networks or individual services appeared to be focused on mental health. The remainder either had a holistic focus based within primary care, or the reports were unclear in their descriptions of the service focus. Services focused on primary care tended to be characterised as primary health services. Most services that had a primary focus on mental health were characterised as being an enhanced blend of primary and more specialised secondary health services. The latter involve a multidisciplinary team approach to augment primary care, tailored specifically to the health and social needs of young people. However, this was often not clearly described in the studies.

\section{Number of people using the service}

Evaluations of the service networks reported that large numbers of young people had accessed the services (Box). Up to 8000 young people accessed a Jigsaw service in Ireland between 2008 and June 2014, with 19389 young people having been seen to date (at time of writing). YOSS in New Zealand had between 28000 and 34000 young people registered as clients at the time of evaluation in 2008. In Australia, more than 80000 young people visited a headspace centre during the 12-month period from July 2016 to June 2017, with a total of 35000 clients also using the eheadspace online and telephone service annually. Maison de Solenn, in Paris, one of the 104 Maisons des Adolescents in France, had 30000 young people access the service in 2016. In Canada, it was estimated that 1000 referrals would be received at the ACCESS OM network during an 8-month period; and Granville Youth Health Centre, the first service established in Foundry's network, had 912 referrals in its first year of operation.

\section{Accessibility}

Most services offered walk-in and self-referral options (no description was given for two services, Youthspace and The Junction), and eight services were reported as offering appointments outside of normal school and business hours (Box). Whether the service had a shop front was seldom reported. Two services (Your Choice and KYDS Youth Development Service) specifically stated that they did not have a shop front. Five 


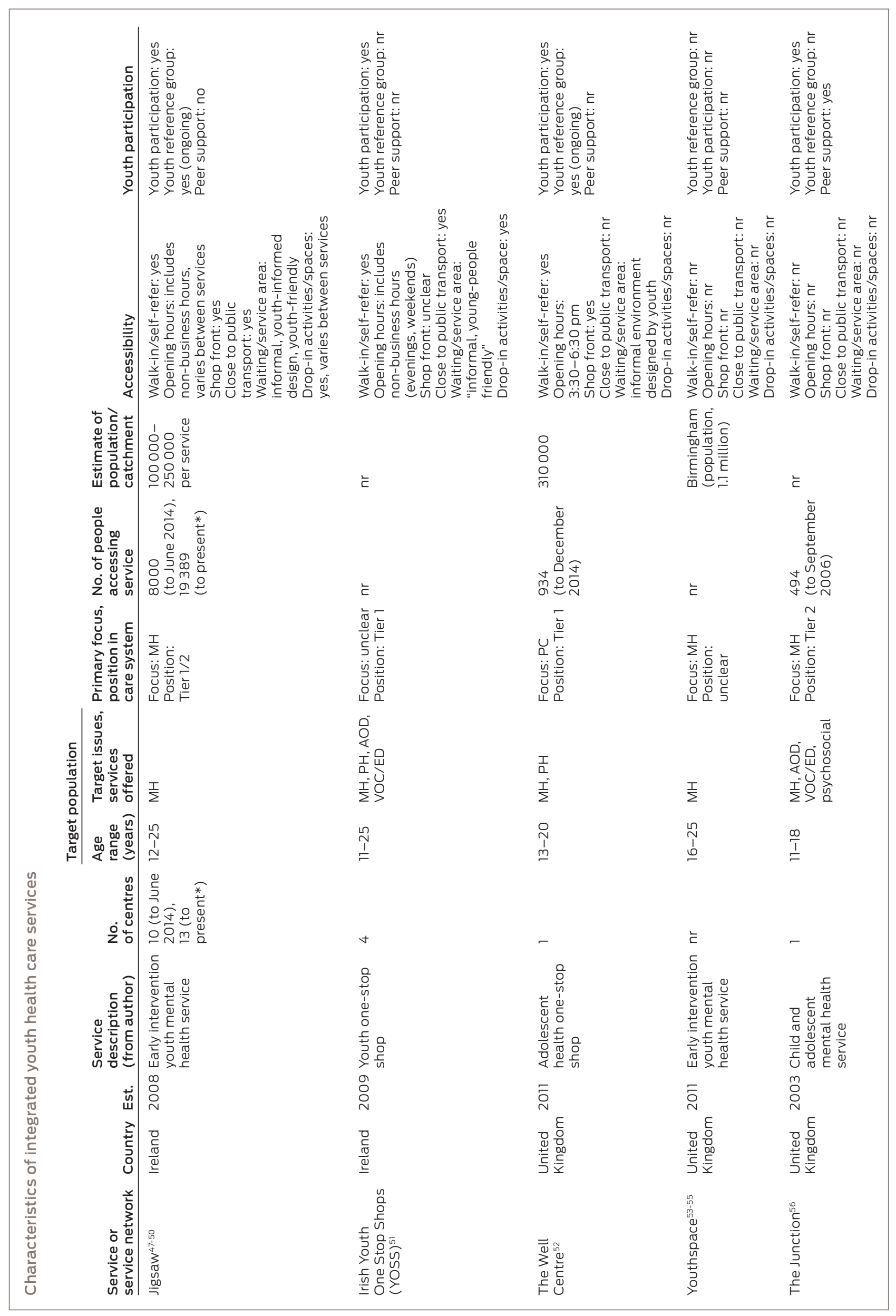




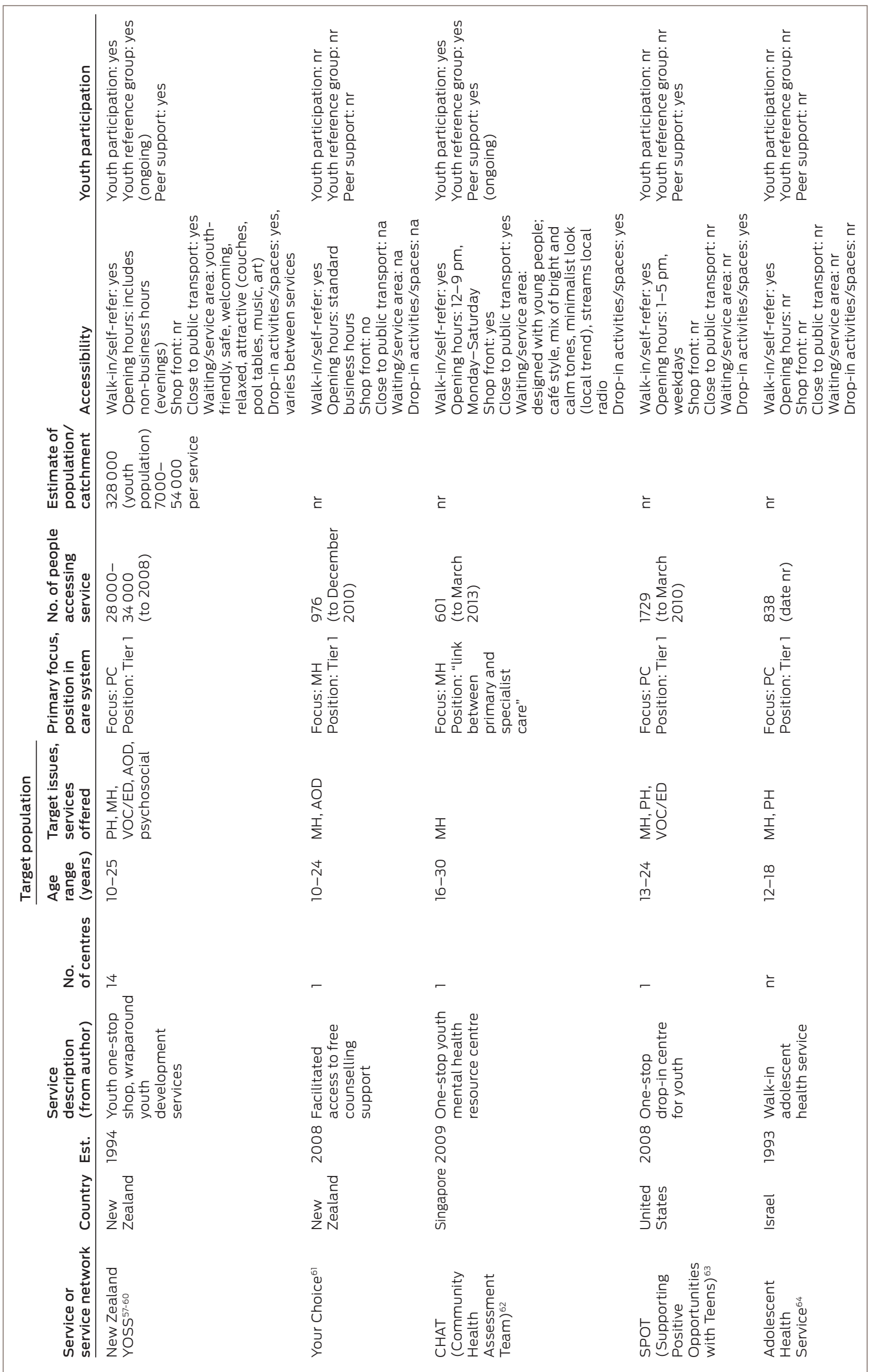

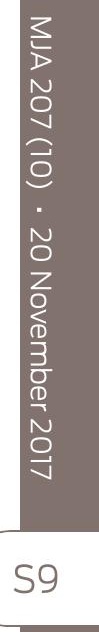




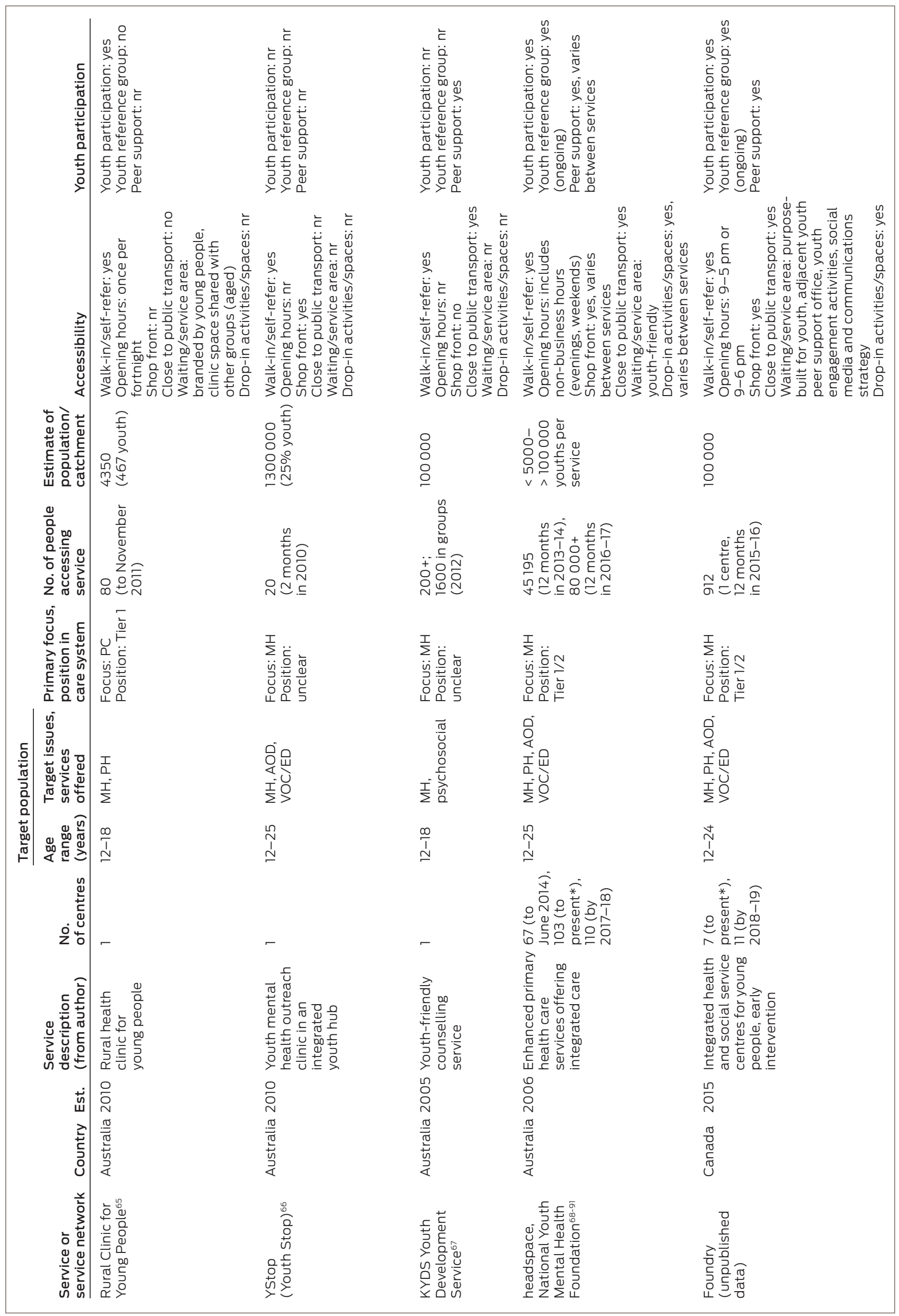




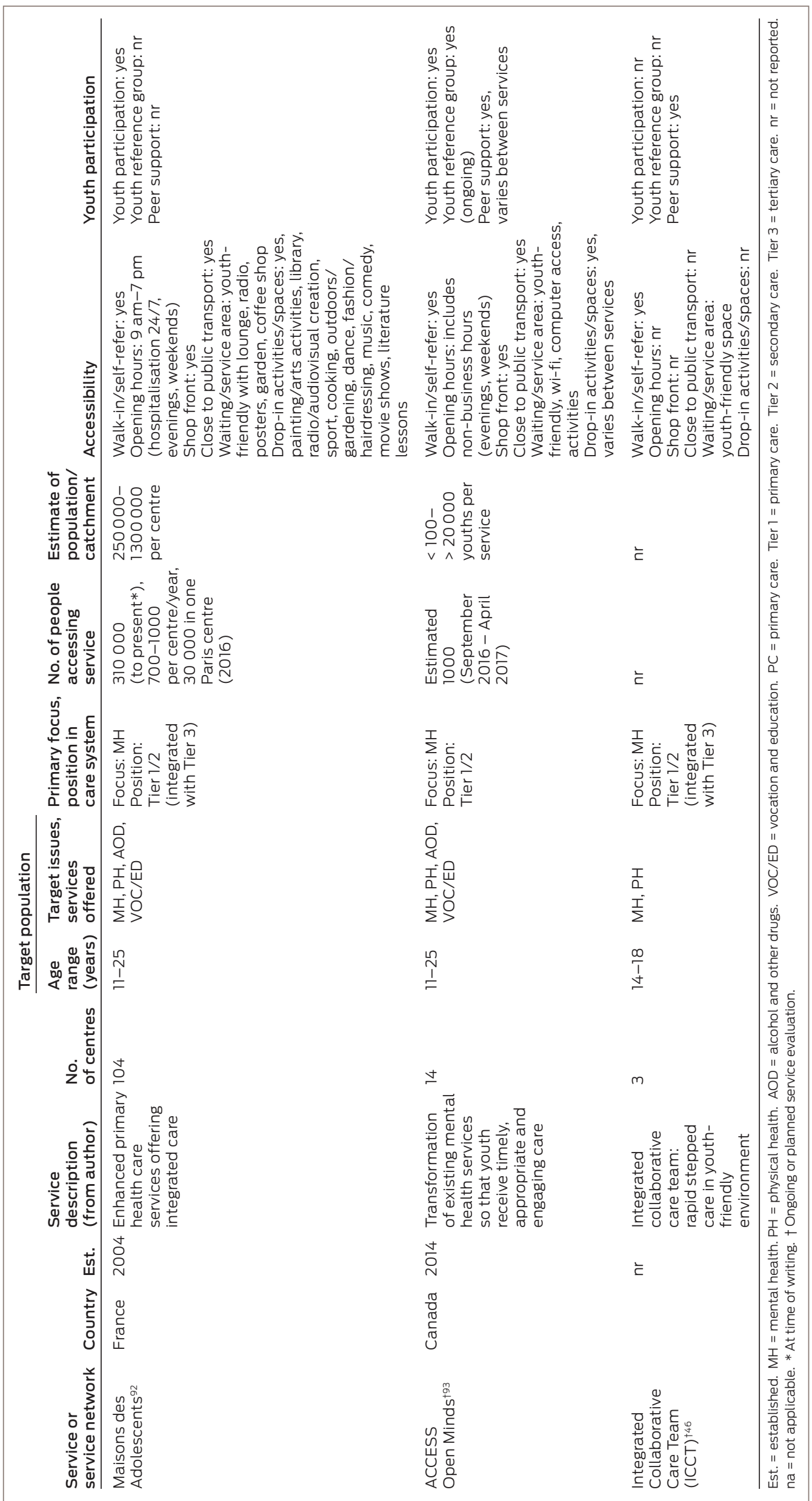


networks or services (CHAT, Jigsaw, Foundry, The Well Centre and Maisons des Adolescents) described a shop front, while this was reported as varying across services in the headspace network. ACCESS OM youth spaces were described as having a variety of structures and formats, with some including a shop front. ${ }^{93}$ Nine services were located close to public transport, one (Rural Clinic for Young People ${ }^{65}$ ) was not, and one (Your Choice $^{61}$ ) provided integrated access to care but did not offer direct services to young people at its physical location.

Although the physical environment of services (waiting area and service area) was not often described, we obtained descriptions from evaluation reports or experts for some services. These were characterised by statements that the environment was youthfriendly or purpose-built for youth, sometimes giving more information about the environment, such as it:

- being "informal” (Jigsaw, Irish YOSS, The Well Centre);

- having "wi-fi, computer access, activities" (ACCESS OM);

- being "decorated/designed by youth" (CHAT, The Well Centre, Jigsaw);

- being "safe, welcoming, relaxed, attractive" (New Zealand YOSS);

- having youth "engagement activities" and a "youth peer support office adjacent to [the] waiting area" (Foundry);

- having "a lounge, radio, posters, garden and a coffee shop" (Maisons des Adolescents);

- having a "café style with mix of bright and calm tones with minimalist look (local trend)" (CHAT); and

- "streaming local radio" (CHAT).

Drop-in facilities were reported as being included in all the Irish YOSS, Foundry, CHAT and SPOT youth spaces, while they were included in only some headspace, Jigsaw, ACCESS $\mathrm{OM}$ and Maisons des Adolescents services. Drop-in services were also reported in the New Zealand YOSS network but were now less common than they had originally been. The ACCESS OM network described drop-in facilities as being a key element of service design. Descriptions of 11 services did not provide any detail about whether drop-in facilities were integral to the service design.

\section{Youth participation}

Youth participation in decision making, leadership, service provision or service development was described in a broad sense in 11 services or service networks, with five networks (Jigsaw, headspace, New Zealand YOSS, Foundry and ACCESS OM) and The Well Centre and CHAT services having permanent youth reference groups (Box). There was little description of this aspect for the other services. Seven services or networks (Foundry, The Junction, New Zealand YOSS, CHAT, SPOT, ICCT and KYDS Youth Development Service) all described offering peer support (ie, peers with or without lived experience providing any kind of support to clients), while headspace and ACCESS OM had peer support available in some of their services. In the remainder, this aspect of service design was not described.

\section{Outcome evaluation}

We located 43 evaluations reporting at least one aspect of an outcome of interest (access; symptomatic and functional outcomes; and satisfaction, acceptability and appropriateness) in
46 articles or documents, plus two ongoing evaluations that have not yet reported any outcomes (online Appendix 1, Appendix 2 and Appendix 3). Nineteen evaluations largely provided a description of the service users and services provided (including one headspace evaluation with descriptions of 10 different services). Types of evaluation undertaken varied in terms of quality but overall were rated as level IV evidence according to the National Health and Medical Council (NHMRC) levels of evidence. ${ }^{94}$ Two studies had at least one component rated as level III-3 evidence, and five were purely qualitative studies (Appendix 1).

\section{Access}

\section{Sample characteristics}

Most services reported attracting young people in the mid to older adolescent age range; however, most studies reporting mean age were evaluations of headspace services, which tended to attract a slightly older demographic (Appendix 1). Only seven of the evaluations did not comment on the age of the young people presenting. ${ }^{54,56,57,64,65,67,82,83}$ The proportion of female clients presenting to the services ranged from $45 \%$ to $100 \%$ (median, $60 \%$ ). Again, the large number of evaluations of headspace weighted this finding, with these services typically attracting a larger proportion of female clients.

Where reported, the ethnicity and other characteristics of presenting young people tended to demonstrate that the services do a good job of attracting traditionally under-served populations. For example:

- Between $20 \%$ and $30 \%$ of the clientele at New Zealand YOSS were Maori (Maori make up 15\% of the New Zealand population), although the proportion of Pacific Islander peoples was smaller. ${ }^{58,59}$

- SPOT reported that $62 \%$ of presenting young people were African American in an area where African Americans comprise $49 \%$ of the catchment, and $58 \%$ of those accessing the service were unemployed. ${ }^{63}$

- Jigsaw services saw a large proportion of young people who were unemployed $(16 \%$, but up to $30 \%$ in the $21-25$-years age group). ${ }^{48,49}$

- At the Well Centre, only $29 \%$ of presenting young people were classified as white in an area where $55 \%$ identify as white..$^{52}$

- The Granville Youth Health Centre (part of Foundry) reported that $17 \%$ of presenting young people were First Nations, 3\% reported being transgender and 30\% were homeless (Steve Mathias, Executive Director, Foundry, unpublished data, 27 June 2017).

Across the various headspace evaluations in Australia, the estimate of Aboriginal or Torres Strait Islander young people ranged from $2.9 \%$ to $18.8 \%,{ }^{71,72,75,76,80,82,86,91}$ with one report highlighting that $8 \%$ of those presenting were of culturally and linguistically diverse backgrounds (other than Aboriginal or Torres Strait Islander). ${ }^{82}$ Between $1.1 \%$ and $23.5 \%$ were reported to identify as lesbian, gay, bisexual, transsexual or intersex. ${ }^{75,80,82}$ Those not engaged in employment, education or training were reported to comprise between $18 \%$ and $32 \%$ of people presenting to headspace, ${ }^{70-72,77,78,86}$ and in one case up to $73 \%,{ }^{73}$ compared with $11 \%$ of this age group in the general population. While homelessness was often not reported in the headspace evaluations, reported estimates ranged from $1.1 \%$ to $11.7 \%$ (Appendix 1). ${ }^{71,80-82,90}$ 


\section{Levels of distress}

Levels of distress were described and defined variably across evaluation reports. In the 13 reports in which these were described, levels were often high, with indications given that problems were in a clinical range (Appendix 2). A Jigsaw study indicated that $87 \%$ of young people reported clinical levels of distress, ${ }^{48,49}$ while a study at The Junction reported more than $50 \%$ of young people had distress levels in the clinical range. ${ }^{56}$ A New Zealand YOSS study classified $58 \%$ of young people as presenting with "some challenges" or as being "at risk or at serious risk", with a quarter of young people having complex needs. ${ }^{58}$ In a study at the Granville Youth Health Centre (Foundry), 77\% were at "high risk", 12\% at "moderate risk" and $11 \%$ at "low risk"; $42 \%$ reported having significant psychological, behavioural or personal problems for which they wanted help, and $28 \%$ had thought about ending their own lives in the past month (unpublished data). In various headspace studies, $69 \%$ to $74 \%$ were classified as having high or very high levels of distress on the Kessler Psychological Distress Scale (K10), indicating the likelihood of a moderate or severe disorder. ${ }^{70,71,86,87}$ Although nearly $20 \%$ of young people at headspace were given a threshold diagnosis (ie, with moderate to severe symptoms), ${ }^{86} 39 \%$ to $52 \%$ were classified as functionally impaired, ${ }^{79,87}$ and between $55 \%$ and $72 \%$ were reported to have considered suicide over the past year. $^{71}$

\section{Presenting issues}

The problems young people presented with were varied (Appendix 2). Given the focus on mental health in this review and in many of the services, and because only the primary reason for attendance was typically recorded, it is perhaps not surprising that presentations were generally related to mental health and psychosocial difficulties, with fewer presentations for physical health or educational and vocational problems. Problems were variously described and included anger issues, stress, family problems, relationship issues, adjustment problems, low mood, depression, mood difficulties, mood disorders, suicide-related behaviour, anxiety, learning difficulties, low self-esteem, alcohol and other drug problems, school issues including bullying, sexual assault and domestic violence. In a few centres (CHAT, ${ }^{62}$ Youthspace, ${ }^{53,55}$ SPOT $^{63}$ and headspace $\left.{ }^{68,69,79}\right)$, young people were reported as presenting with first-episode psychosis, psychosis or (more commonly) being "at risk of" psychosis. Eating disorders were seen at headspace centres ${ }^{74,79}$ but were a focus at the Paris Maison de Solenn, ${ }^{92}$ where young people were also reported to be presenting with impaired attention, antisocial behaviour and other personality disorders. The Adolescent Health Service in Israel was unusual in having a more physical health focus. ${ }^{64}$

\section{Services received}

The most common intervention described was individual counselling (Appendix 2). This was typically brief, with six of 17 evaluation reports suggesting about four sessions were received ${ }^{48,52,71,75,85,92}$ (range, $2 \cdot 6^{80}$ to $15^{71}$ ). Although there are fiscal constraints on the number of free sessions available in the headspace services, there was an indication from several evaluations that more intensive treatment was provided for young people who presented with more severe issues. ${ }^{68,69,71}$

\section{Symptomatic and functional outcomes}

In 13 of the 43 evaluations included in the review, clinical outcomes were reported for seven services or service networks: in one evaluation each of Jigsaw, ${ }^{48,49}$ Youthspace, ${ }^{54}$ Irish YOSS, ${ }^{51}$
Your Choice ${ }^{61}$ and Foundry (unpublished data); two evaluations of New Zealand YOSS, including one of the whole network ${ }^{59}$ and one of an individual service, ${ }^{58}$ and five from the headspace network or its individual services ${ }^{68,71,75,78,84}$ (Appendix 3).

There were eight studies using pre- and post-measurement of symptoms and functioning, which evaluated an individual headspace service or the headspace network, ${ }^{68,71,78,84}$ a New Zealand YOSS service, ${ }^{58}$ Your Choice, ${ }^{61}$ Jigsaw, ${ }^{48,49}$ Youthspace $^{54}$ and Foundry (unpublished data). The evaluations of New Zealand services indicated positive outcomes. In the Your Choice service study, young people experienced significant reductions in symptoms and substance use and improvements in functioning. ${ }^{61}$ In the Kapiti YOSS service in New Zealand, $94 \%$ of young people presenting with some difficulties and $97 \%$ of those with complex needs experienced improvements $(52 \%$ and $58 \%$, respectively) or remained the same $(42 \%$ and $39 \%$, respectively) in the short term. ${ }^{58}$ An evaluation of Jigsaw in Ireland found that $62 \%$ of $17-25$-year-olds and $68 \%$ of $12-16$-yearolds showed improvements in wellbeing and functioning. ${ }^{48,49} \mathrm{~A}$ study of Youthspace in the UK found that $8.8 \%$ of young people experienced a decline in mental health and wellbeing, while $57.6 \%$ improved and $33.6 \%$ remained the same. ${ }^{54}$ Evaluations undertaken at headspace also found that some young people showed no improvement on the K10 measure of psychological distress. In one such study, $60 \%$ of young people using the service demonstrated a reduction in symptoms or improvements in functioning, while $13 \%$ experienced worsening symptoms and $20 \%$ experienced a decline in functioning. ${ }^{84}$ Results indicated that levels of improvement were higher when more treatment sessions were received. The most recent evaluation of headspace found that just over $20 \%$ of young people experienced a clinically significant or reliable improvement in K10 scores (ie, a reduction in distress) and again highlighted that young people who had received only two or three treatment sessions were overrepresented among those who had no or insignificant reductions in distress levels. ${ }^{71}$

One evaluation compared young people treated at headspace with a matched sample who had received treatment elsewhere, and showed that the headspace group had a significantly greater reduction in distress based on K10 scores (effect size, $\mathrm{d}=-0.16$ ); similarly, those treated at headspace had a significantly greater reduction in distress on K10 scores compared with a group of young people who had received no treatment (effect size, $\mathrm{d}=-0.11) .{ }^{71}$ Suicidal ideation and self-harm were reduced in those whose K10 distress scores improved; however, suicidal ideation also dropped from $64.0 \%$ to $47.8 \%$ and self-harm from $39.9 \%$ to $30.6 \%$ even among those who did not experience any change in K10 scores. ${ }^{71}$ A further evaluation of a single headspace centre found that significant improvements in psychological distress levels were experienced equally by those with varying degrees of difficulties, but that those who had more severe symptoms and impaired functioning at intake were likely to still be impaired at follow-up. ${ }^{68,69}$ An evaluation of the headspace network indicated that the impact of these services could be maximised by ensuring more specialist expertise was made available for those who needed it. ${ }^{71}$

When a survey design was used in evaluation, the results were overwhelmingly positive, with young people stating that their mental health had improved $(77 \%$ in Foundry [unpublished data], $92 \%$ in headspace ${ }^{75,91}$ ), that the service had been able to help them $\left(88 \%\right.$ in the Irish YOSS $\left.{ }^{51}\right)$ or that the service was effective in helping them $\left(94 \%\right.$ in New Zealand YOSS $\left.{ }^{59}\right)$. Young people 
also indicated that the service they had received had helped to improve their school or work engagement (70\% in Foundry [unpublished data], $79.2 \%$ of young adolescents and $47.8 \%$ of young adults in headspace $\left.{ }^{75,91}\right)$, their confidence and self-esteem (94\% and 93\%, respectively, in the Irish YOSS; ${ }^{65} 60 \%$ reported improved confidence in Youthspace ${ }^{54}$ ) and their physical health (54\% in headspace, ${ }^{75,91} 68 \%$ in Foundry [unpublished data]) (Appendix 3).

\section{Satisfaction, acceptability and appropriateness}

In 17 of the 43 included evaluations, outcomes relevant to the satisfaction of users and acceptability and appropriateness of the services to users were reported (Appendix 3). When measured, generally high levels of satisfaction were reported (Foundry, unpublished data). ${ }^{51,55,56,58-61,71,73-76,80-82,92}$ In particular, young people reported satisfaction with the staff providing the services, $51,59,61,71,75,76,81,91$ stating that they valued these relationships and noting the importance of staff who were friendly, non-judgemental and respectful, ${ }^{51,59,71}$ who genuinely liked young people ${ }^{58}$ and who were able to understand issues young people presented with. ${ }^{59,61}$ Young people in one study reported that the staff in the service were the reason they used the service. ${ }^{59}$ Another evaluation used "did not attend" rates as a proxy for satisfaction and reported that these rates were reduced in the integrated youth health care service compared with usual service. ${ }^{53,55}$

A recurring finding was that young people found (and appreciated) that services were accessible, acceptable and appropriate. ${ }^{56,58-60,71,76,80}$ The specific aspects of a service that were identified as representing accessibility, acceptability and appropriateness were:

- having a convenient and appropriate location (access to public transport was noted as being useful); $49,57,71,74,78$

- being youth-friendly (staff and environment) and welcoming; $51,56,59,71,74-76,80,91,92$

- being staffed by young people, ${ }^{58,80}$

- having appointments made in a timely way; ${ }^{61,76}$

- being low cost; ${ }^{58,59,71,76}$

- maintaining confidentiality and privacy; ${ }^{51,58,59,76}$

- having a wide range of integrated services available in one place, with non-mental health-related signage (Foundry, unpublished data), ${ }^{58,59,71,76,80,92}$ and

- delivering safe and appropriate interventions in a positive and strengths-based framework (Foundry, unpublished data). ${ }^{58,59,61,80}$

There was less satisfaction with opening hours, which were often limited to daytime office hours, ${ }^{51,76}$ and long waiting lists were noted as a potential problem that could affect satisfaction, acceptability and appropriateness. ${ }^{73,81}$ Evaluation reports indicated that satisfaction would be improved if a more timely service (shorter wait time) could be provided..$^{53,55,85}$ Also of note was an indication from some evaluation reports (New Zealand YOSS $^{59}$ and headspace ${ }^{71,80}$ ) that stigma remains an issue in terms of accessing services, with suggestions that appropriate signage is important in reducing the potential impact of stigma.

\section{Other outcomes}

In nine of the 43 evaluations, other relevant outcomes were reported. These included reports that young people welcomed the kinds of interventions provided by these services and were able to learn skills that they used in the long term. ${ }^{53} \mathrm{~A}$ common finding across the New Zealand YOSS network was that, without these services, young people would not have accessed physical or mental health services, ${ }^{57-59}$ reinforcing the description in one report that these services are unique and indispensible. ${ }^{51}$ Not only do young people appreciate these services, but indications in the reports that the services have been well adapted to local needs suggest that so do the communities in which they are embedded..$^{71,83}$

\section{Discussion}

Integrated youth health care services are represented by various models of care, but all are designed to overcome the problem of poor access to services for young people. Given the concerning paucity of evaluations of other models of service delivery, such as general practice in Australia, it is encouraging that we identified a considerable number of service evaluations to include in this review. The nature of the included evaluations was typical of health service evaluations (overall rated as level IV in the NHMRC evidence hierarchy ${ }^{94}$ ) as, given the impetus to ensure all young people receive a high quality of care, randomised controlled trials are often unacceptable and unfeasible.

Ensuring accessibility is an important principle of integrated youth health care services. Services were largely described as having characteristics in line with those typically credited with increasing access, including offering walk-in sessions and selfreferral, being located centrally or close to public transport, and providing designated drop-in spaces and activities. The key potential limitations in terms of accessibility were long waiting lists (due to high demand) and limited opening hours that are perhaps better suited to the service providers than to young people. Descriptions of services as youth cafés or having a shop front were rare, and the specifics of service environments were seldom described. The descriptions that did exist highlighted efforts to ensure that young people would be attracted to, and comfortable in, the service. It was notable that young people still perceive stigma regarding mental health difficulties and appreciate non-mental health-related signage, suggesting that the less services look like clinical services, the better. Although not specifically addressed in this review, the large networks of services have a focus on brand (eg, Jigsaw, headspace, Foundry), and this aspect of service design, linked to a well formulated and implemented communication strategy (marketing), has been seen by those implementing these services and other youth mental health initiatives as essential to increasing accessibility and trust. ${ }^{95}$

Overall, services were addressing the "major design flaw"41 of current services, where there is a discontinuity at the age of 18 years between child and adolescent services and adult services, resulting in many young people falling through the gap. The services included in the review were open to a wide range of ages, with most seeing young people up to the age of 24 or 25 years. These services also appear to be attracting and engaging typically under-served populations, although access for some of these subgroups can be further improved to ensure that the proportion of these young people seen is commensurate with the level of mental health difficulties they experience. Importantly, however, it appears that young people who would not otherwise access any type of physical or mental health service are using these integrated youth health care services. Young people 
who used these services felt they benefited from them, were generally highly satisfied with their experience and valued a range of features characteristic of integrated youth health care services, particularly the relationships they were able to form with the staff. This is consistent with evidence that the quality of relationships with providers can be as important to outcomes as the content of the service delivered and reflects a positive youth development model. ${ }^{96}$ Young people also appreciated services that were staffed by young people, and although peer support (ie, young people working as support workers) was less common, youth participation more generally was reported in just over half of the services. Youth participation has been described as a critical ingredient for integrated youth health care services, 7,31,97,98 and, consistent with the literature, was highly valued by young people.

While there was a mixture of clinical and non-clinical presentations of varying levels of distress, a high proportion of young people accessing these services presented with difficulties of a serious nature and high levels of distress. However, the available data on symptomatic and functional improvement are generally promising. Across the included service evaluations, between $52 \%$ and $68 \%$ of young people experienced reductions in symptoms, with some of the most adverse outcomes of mental health problems (suicidal ideation, self-harm and impaired social and vocational functioning) being ameliorated. Young people also self-reported improvements in their mental health, educational and vocational pursuits, confidence and self-esteem, and physical health following involvement with the services.

However, the data also indicate that a proportion of young people who accessed the services failed to benefit or even experienced a decline in their condition. This is not surprising, given that the integrated care model is generally an entrylevel enhanced primary care model where mental health and other social care services are added to primary physical health services. There is some evidence that the young people who do not respond favourably are those with more severe symptoms and functional impairment and those who attend for fewer sessions. Therefore, greater emphasis on engagement with the group with more severe presentations is required, including more intensive and outreach-based services and more sustained and expert care. Fiscal constraints typically lead to delivery of briefer interventions (eg, headspace can only provide up to 10 sessions at no cost to the young person, with average attendance of four sessions ${ }^{85}$ ). These services are attracting young people with severe and complex difficulties as well as those with earlier and milder cases of mental illness. As such, they need to be appropriately resourced, as well as being integrated seamlessly with secondary and tertiary care to ensure the needs of all presenting young people are addressed. At the same time, specialist services need to ensure the principles of youth health care are adopted into their service models and practices, which will further support seamless care for young people.

Our review has some limitations. First, as there are multiple difficulties in undertaking evaluations in these kinds of services, the limited amount of outcome data available in this review is an issue. There are difficulties associated with measuring outcomes, given the diversity and complexity of presenting issues, so functional outcomes and outcomes important to young people may not be measured or routinely collected. There are also difficulties in long-term tracking of young people, particularly in services where anonymity may be valued. Difficulties with evaluation procedures (eg, full informed research consent) are problematic, as adhering to clinical trial standards, which may not be appropriate for health service evaluation, can be incompatible with a service being youth-friendly and acceptable. There may also be service capacity limitations in terms of time and resources to undertake assessments, as well as limits to service sustainability due to lack of funding. Often these services have not been set up as demonstration and evaluation projects, so embedding evaluation is challenging. An exception to this is the ACCESS OM network, where an evaluation is underway in multiple sites representing the geographic, population and cultural diversity of Canada. ${ }^{93}$

A further limitation is the variable quality of the included studies. We are also aware that there are many other integrated youth health care services in operation that may also be collecting data, but they have not published these in a way that we were able to access. The types of services we excluded also represent a gap in this review. For example, many school-based services include a range of professionals to address the needs of young people in a holistic way, and sexual health clinics also often act as primary care services for young people and in many cases undertake mental health screening. Finally, some groups (eg, homeless people and those disengaged from school, family or work) are less likely to engage in activities that gauge satisfaction with and acceptability and appropriateness of the services, potentially limiting the generalisability of our findings in this domain. Given these limitations, it is not yet possible to definitively state whether these types of integrated youth health care services are effective.

Although further research is needed, the traditional approach to establishing an evidence base for individual treatments is too rigid and not sufficiently relevant for health services research. ${ }^{41}$ Whether these types of services are effective may be too simplistic a research question. We need to ask, in comparison to what? Access to traditional primary care for young people seeking help for mental health difficulties is poor, and those who do access it are likely to represent a very different demographic to those who access integrated services. Governments and funders have scaled up services in such a way as to impede the most rigorous forms of evaluation, such as stepped wedged randomised designs and large-scale randomised controlled trials. The services or networks of services have similarities but also important differences, highlighting their evolution within their historical, philosophical, cultural, fiscal and political contexts. For example, the New Zealand YOSS arose out of a youth developmental model within the Maori Whare Tapa Wha model of health; ${ }^{99,100}$ they are not explicitly mental health services, compared with the ACCESS OM, Jigsaw and headspace models, which have in part drawn on the early intervention in psychosis model. ${ }^{14}$ One of the major Maisons des Adolescents models in Paris, the Maison de Solenn, was initially driven by a perceived need to ensure that young people with eating disorders received appropriate services and to provide a service to improve family functioning for young people..$^{92}$

It is also true that, even within service networks, what is offered in individual services is likely to vary, with further variations in the interventions offered between individual clinicians and staff. This means that the interventions delivered across integrated youth health care services are imprecisely defined and delivered. This needs to be overcome with clearer service specifications, templates, accreditation mechanisms and standardised clinical governance. The balance and tension between service model fidelity or standard features and local adaptability is likely to 
be stabilised in the next phase of evolution, particularly in Australia with the devolution of commissioning of primary health services to the regional primary health network level. ${ }^{101}$ In this new model, the regional primary health network will be responsible for commissioning youth mental health services, including headspace services in its region. In this context, what is likely to be a more useful research question is: "Which young people, with what needs, receiving what specific interventions in what degree, experience what types of outcomes?" For example, studies have shown that young people who receive interventions from staff with postgraduate training in youth health have improved mental health and wellbeing. ${ }^{102}$

In our literature review, we found that some core features of these types of services were poorly defined or described, such as the definition of a timely first assessment or a youth-friendly environment, and the nature of integration and governance structures to ensure this integration. Although integration is a key defining characteristic of these services, it can occur in a range of ways. We found inadequate descriptions of integration in the publications and evaluation reports we obtained. Understanding which core services and ancillary services, and the nature of their integration, would best ensure holistic care for young people would be of value. ${ }^{26}$ International collaboration to undertake research that examines the impact of various aspects of service organisation and the delivery of integrated youth health care services would clarify the principles and objectives of these services. It would also allow for development of frameworks or standards to facilitate the benchmarking of services for ongoing quality improvement. ${ }^{103}$ Further consideration needs to be given to the nature of evaluation that is undertaken in these services, to ensure that the outcomes are those that are important to stakeholders - considering not just clinicians and young people, but also decision makers and funders, who may be more interested in feasibility, cost, penetration and sustainability. ${ }^{104}$
In conclusion, integrated youth health care services are multilayered models of care focusing on the highly diverse needs of a broad segment of the population (people aged 12-25 years). This literature review highlights the many different approaches or models that have been implemented, with no single example yet constituting best practice. This in itself highlights one of the strengths of the model - of being able to adapt to the local context and meet local needs. The findings of our literature review indicate that the key aim of increasing access and addressing the crisis in care for this age group is being realised, with care being provided to large numbers of young people. The data indicate that young people rate the services positively and, without these services, they may not have otherwise sought help. While these and other promising outcomes have been described, further investment in definition of service standards, frameworks, governance and outcome evaluation is needed to develop service delivery models that will address the full spectrum of difficulties with which young people present, including severe problems and high levels of psychological distress.

\section{Competing interests: Patrick McGorry is the executive director of, and Sarah Hetrick} and Alan Bailey are clinical researchers at, Orygen, the National Centre of Excellence in Youth Mental Health, which is the lead agency for four headspace centres; Patrick McGorry is also a director of the board of headspace, the National Youth Mental Health Foundation. Kirsten Smith is a former director of Evolve Youth Services. Ashok Malla is the director of ACCESS OM. Steve Mathias is the director of Foundry. Swaran Singh is the director of Youthspace. Aileen O'Reilly is the research coordinator at Jigsaw. Swapna Verma is the director of CHAT. Laelia Benoit is a psychiatrist in, and Marie Rose Moro is the director of, the Paris Maison de Solenn. Debra Rickwood is the chief scientific advisor at headspace. Joseph Duffy is the chief executive officer of Jigsaw. Trissel Eriksen is the director of the Youth One Stop Shop in Palmerston North, New Zealand, and is on the executive of the Network of Youth One Stop Shops, New Zealand. Robert Illback is the chief executive officer of REACH of Louisville and is a former deputy chief executive officer of Jigsaw.

Provenance: Commissioned; externally peer reviewed.
1 Gore FM, Bloem PJ, Patton GC, et al. Global burden of disease in young people aged $10-24$ years: a systematic analysis. Lancet 2011; 377: 2093-2102.

2 Kessler RC, Berglund P, Demler O, et al. Lifetime prevalence and age-of-onset distributions of DSM-IV disorders in the National Comorbidity Survey replication. Arch Gen Psychiatry 2005; 62: 593-602.

3 Fergusson DM, Horwood LJ. The Christchurch Health and Development Study: review of findings on child and adolescent mental health. Aust N Z J Psychiatry 2001; 35: 287-296.

4 Bloom DE, Cafiero ET, Jané-Llopis E, et al. The global economic burden of non-communicable diseases. Geneva: World Economic Forum, 2011. http://apps.who. int/medicinedocs/en/d/Js18806en/ (accessed Sep 2017).

5 Gibb SJ, Fergusson DM, Horwood LJ. Burden of psychiatric disorder in young adulthood and life outcomes at age 30 . Br J Psychiatry 2010; 197: 122-127.

6 Copeland W, Shanahan L, Costello EJ, et al. Cumulative prevalence of psychiatric disorders by young adulthood: a prospective cohort analysis from the Great Smoky Mountains Study. J Am Acad Child Adolesc Psychiatry 2011; 50: 252-261.

7 Anderson JE, Lowen CA. Connecting youth with health services: systematic review. Can Fam Physician 2010; 56 : 778-784.

8 Viner RM, Barker M. Young people's health: the need for action. BMJ 2005; 330: 901-903.

9 Watson PD, Clark TC, Denny SJ, et al. A health profile of New Zealand youth who attend secondary school. NZ Med J 2003; 116: U380.
10 Wang PS, Berglund P, Olfson M, et al. Failure and delay in initial treatment contact after first onset of mental disorders in the National Comorbidity Survey Replication. Arch Gen Psychiatry 2005; 62: 603-613.

11 Lawrence D, Johnson S, Hafekost J, et al. The mental health of children and adolescents. Report on the second Australian Child and Adolescent Survey of Mental Health and Wellbeing. Canberra: Department of Health, 2015. http://www.health.gov.au/internet/main/publishing.nsf/ content/mental-pubs-m-child2 (accessed Sep 2017).

12 Canadian Association of Paediatric Health Centres; National Infant, Child, and Youth Mental Health Consortium Advisory; Provincial Centre of Excellence for Child and Youth Mental Health at CHEO. Access \& wait times in child and youth mental health: a background paper. Ottawa: Ontario Centre of Excellence for Child and Youth Mental Health, 2010. http://www. excellenceforchildandyouth.ca/resource-hub/accessand-wait-times-child-and-youth-mental-healthbackground-paper (accessed Sep 2017).

13 Chong SA, Abdin E, Vaingankar JA, et al. Where do people with mental disorders in Singapore go to for help? Ann Acad Med Singapore 2012; 41: 154-160.

14 Malla A, Iyer S, McGorry P, et al. From early intervention in psychosis to youth mental health reform: a review of the evolution and transformation of mental health services for young people. Soc Psychiatry Psychiatr Epidemiol 2016; 51: 319-326.

15 McGorry P, Bates T, Birchwood M. Designing youth mental health services for the 21st century: examples from Australia, Ireland and the UK. Br J Psychiatry Suppl 2013; 54: s30-s35.
16 Bonnie RJ, Stroud CE, Breiner H. Investing in the health and well-being of young adults. Washington, DC. The National Academies Press, 2015.

17 McGorry PD, Purcell R, Goldstone S, et al. Age of onset and timing of treatment for mental and substance use disorders: implications for preventive intervention strategies and models of care. Curr Opin Psychiatry 2011; 24: 301-306.

18 McGorry PD. The specialist youth mental health model: strengthening the weakest link in the public mental health system. Med J Aust 2007; 187 (7 Suppl): S53-S56. https://www.mja.com.au/journal/2007/187/7/specialistyouth-mental-health-model-strengthening-weakestlink-public-mental

19 Arnett JJ, Žukauskiene R, Sugimura K. The new life stage of emerging adulthood at ages $18-29$ years: implications for mental health. Lancet Psychiatry 2014; 1: 569-576.

20 Porter ME, Lee TH. The strategy that will fix health care. Harvard Business Review 2013; 91: 50-70.

21 Garcia I, Vasiliou C, Penketh K. Listen up! Person-centred approaches to help young people experiencing mental health and emotional problems. London: Mental Health Foundation, 2007. https://www.mentalhealth.org.uk/ publications/listen (accessed Sep 2017).

22 World Health Organization. The world health report 2001. Mental health: new understanding, new hope. Geneva:WHO, 2001. http://www.who.int/whr/2001/en/ (accessed Sep 2017).

23 World Health Organization. Global burden of mental disorders and the need for a comprehensive, coordinated response from health and social sectors at the country level (EBI30.R8). Geneva: WHO, 2012. http://www. who.int/gb/ebwha/pdf_files/EB130/B130_R8-en.pdf (accessed Sep 2017). 
24 Tyler ET, Hulkower RL, Kaminski JW. Behavioral health integration in pediatric primary care: considerations and opportunities for policymakers, planners and providers. New York: Milbank Memorial Fund, 2017. https://www. milbank.org/publications/behavioral-health-integrationin-pediatric-primary-care-considerations-andopportunities-for-policymakers-planners-and-providers/ (accessed Sep 2017).

25 Asarnow JR, Rozenman M, Wiblin J, Zeltzer L. Integrated medical-behavioral care compared with usual primary care for child and adolescent behavioral health: a metaanalysis. JAMA Pediatr 2015; 169: 929-937.

26 Collins C, Hewson DL, Munger R, Wade T. Evolving models of behavioral health integration in primary care. New York: Milbank Memorial Fund, 2010. https:// www.milbank.org/publications/evolving-modelsof-behavioral-health-integration-in-primary-care/ (accessed Sep 2017).

27 Kodner DL, Spreeuwenberg C. Integrated care: meaning, logic, applications, and implications - a discussion paper. Int J Integr Care 2002; 2: el2.

28 Rosenberg S, Hickie I. Managing madness: mental health and complexity in public policy. Evidence Base 2013; 3: $1-19$.

29 Ellis LA, Churruca K, Braithwaite J. Mental health services conceptualised as complex adaptive systems: what can be learned? Int J Ment Health Syst 2017; 11: 43.

30 Grone 0, Garcia-Barbero M. Integrated care: a position paper of the WHO European Office for Integrated Health Care Services. Int J Integr Care 2001; 1: e21.

31 Fleming T, Elvidge JM. Youth health services literature review. A rapid review of: school based health services, community based youth specific health services \& general practice health care for young people. Auckland: Waitemata District Health Board, 2010

32 Appleton P. Tier 2CAMHS and its interface with primary care. Adv Psychiatr Treat 2000; 6: 388-396.

33 Tynan WD, Woods KE. Emerging issues: psychology's place in the primary care pediatric medical home. Clin Pract Pediatr Psychol 2013; 1: 380-385.

34 Kramer T, Garralda ME. Child and adolescent mental health problems in primary care. Adv Psychiatr Treat 2000; 6: 287-294.

35 Bower P. Primary care mental health workers: models of working and evidence of effectiveness. Br J Gen Pract 2002; 52: 926-933.

36 Bower P, Garralda E, Kramer T, et al. The treatment of child and adolescent mental health problems in primary care: a systematic review. Fam Pract 2001; 18: 373-382.

37 Tylee A, Haller DM, Graham T, et al. Youth-friendly primary-care services: how are we doing and what more needs to be done? Lancet 2007; 369: 1565-1573.

38 Mathias K. Youth-specific primary health care-access, utilisation and health outcomes: a critical appraisal of the literature. Christchurch: New Zealand Health Technology Assessment, 2002. http://nzhta.chmeds. ac.nz/publications/youth.pdf (accessed Sep 2017).

39 World Health Organization. Global consultation on adolescent friendly health services: a consensus statement. Geneva: WHO, 2001. http://www.who.int/ maternal_child_adolescent/documents/fch_cah_02_18/ en/ (accessed Sep 2017).

40 World Health Organization. Making health services adolescent friendly: developing national quality standards for adolescent friendly health services. Geneva: WHO, 2012. http://apps.who.int/iris/ bitstream/10665/75217/1/9789241503594_eng.pdf (accessed Sep 2017).

41 McGorry PD, Goldstone SD, Parker AG, et al. Cultures for mental health care of young people: an Australian blueprint for reform. Lancet Psychiatry 2014; 1: 559-568.

42 Simmons M, Hetrick S, Jorm A. Shared decision making: benefits, barriers and current opportunities for application. Australas Psychiatry 2010; 18: 394-397.

43 Social Policy Evaluation and Research Unit (Superu). Youth Mental Health Project: research review. Wellington: Superu, 2015. http://www.superu.govt.nz/publication/ youth-mental-health-project-research-review-report (accessed Sep 2017).

44 Ministry of Children and Family Development. Designing mental health service delivery to better meet the needs of youth. Canada: MCFD, 2015

45 Mahood Q, Van Eerd D, Irvin E. Searching for grey literature for systematic reviews: challenges and benefits Res Synth Methods 2014; 5: 221-234.

46 Henderson JL, Cheung A, Cleverley K, et al. Integrated collaborative care teams to enhance service delivery to youth with mental health and substance use challenges: protocol for a pragmatic randomised controlled trial. $B M$ Open 2017; 7: e014080.

47 Illback RJ, Bates T. Transforming youth mental health services and supports in Ireland. Early Interv Psychiatry 2011; 5 Suppl 1: 22-27.

48 O'Keeffe L, O'Reilly A, O'Brien G, et al. Description and outcome evaluation of Jigsaw: an emergent Irish mental health early intervention programme for young people. Ir J Psychol Med 2015; 32: 71-77.

49 O'Reilly A, Illback R, Peiper N, et al. Youth engagement with an emerging Irish mental health early intervention programme (Jigsaw): participant characteristics and implications for service delivery. J Ment Health 2015; 24 283-288.

50 Peiper N, Illback RJ, O'Reilly A, et al. Latent class analysis of need descriptors within an Irish youth mental health early intervention program toward a typology of need. Early Interv Psychiatry 2017; 11: 37-46.

51 Social Market Research. Evaluation of pilot one stop shop programme: final report. Belfast: Public Health Agency; 2011. http://publichealthagency.org/publications/ evaluation-pilot-one-stop-shop-programme (accessed Sep 2017).

52 Hagell A, Lamb S. Developing an integrated primary health care and youth work service for young people in Lambeth: learning from the Well Centre. J Child Serv 2016; 11: 233-243.

53 Singh S, Birchwood M, Lewis P, et al. Early intervention in young people's mental health (part 1): evidence based development of an innovative young people's mental health service and an understanding of facilitators and barriers to its wider implementation. Warwick: West Midlands South Health Innovation and Education Cluster, 2012

54 Singh S, Lewis P, McGruer F, et al. Early intervention in young people's mental health (part 2). Warwick: West Midlands South Health Innovation and Education Cluster, 2013.

55 Vyas NS, Birchwood M, Singh SP. Youth services: meeting the mental health needs of adolescents. Ir J Psychol Med 2015; 32: 13-19.

56 Walker S. A description of the establishment of a new child and adolescent mental health service in the United Kingdom. J Child Adolesc Ment Health 2010; 22: 35-39.

57 Bagshaw S. Survey of the Network of Youth Health Service Providers (NYHSP): affiliated to New Zealand Association for Adolescent Health and Development (NZAAHD). N Z Med J 2006; 119: U2266.

58 Bailey R, Torrie R, Osborne R, et al. How we know what we're doing works. Measuring youth outcomes at Kapiti Youth Support: impact evaluation - summary report 2013. New Zealand: Evaluation Works, 2013. http:// evaluationworks.co.nz/wp-content/uploads/SummaryReport-KYS-Impact-evaluation.pdf (accessed Sep 2017).

59 Communio. Evaluation of Youth One Stop Shops: final report version 1.1. Wellington: New Zealand Ministry of Health, 2009. http://www.health.govt.nz/publication/ evaluation-youth-one-stop-shops (accessed Sep 2017).

60 Geddes N. A consumer satisfaction evaluation for the 198 Youth Health Centre [Masters of Public Health dissertation]. Dunedin: University of Otago, 1997.

61 Clark TC, Johnson EA, Kekus M, et al. Facilitating access to effective and appropriate care for youth with mild to moderate mental health concerns in New Zealand. J Child Adolesc Psychiatr Nurs 2014; 27: 190-200.
62 Poon LY, Tay E, Lee YP, et al. Making in-roads across the youth mental health landscape in Singapore: the Community Health Assessment Team (CHAT). Early Interv Psychiatry 2016; 10: 171-177.

63 Kaushik G, Plax KL, Constantino JN, et al. Mental health care utilization at a free drop-in youth center in St. Louis, Missouri. Mo Med 2012; 109: 475-481.

64 Wilf-Miron R, Sikron F, Glasser S, et al. Community-based adolescent health services in Israel: from theory to practice. Int J Adolesc Med Health 2002; 14: 139-144.

65 Ervin K, Phillips J, Tomnay J. Establishing a clinic for young people in a rural setting: a community initiative to meet the needs of rural adolescents. Aust J Prim Health 2014; 20: 128-133.

66 Lee VW, Murphy BP. Broadening the early intervention paradigm: a one stop shop for youth. Early Interv Psychiatry 2013; 7: 437-441.

67 Citer D, Carlson K, McClellan D, et al. "KYDS": an innovative service addressing the health needs of youth and families in an Australian community. Australas Psychiatry 2013; 21: 131-136.

68 Cross SP, Hermens DF, Hickie IB. Treatment patterns and short-term outcomes in an early intervention youth mental health service. Early Interv Psychiatry 2016; 10: 88-97.

69 Cross SP, Hermens DF, Scott J, et al. Differential impact of current diagnosis and clinical stage on attendance at a youth mental health service. Early Interv Psychiatry 2017; 11: 255-262.

70 Hamilton BA, Naismith SL, Scott EM, et al. Disability is already pronounced in young people with early stages of affective disorders: data from an early intervention service. J Affect Disord 2011; 131: 84-91.

71 Hilferty F, Cassells R, Muir K, et al. Is headspace making a difference to young people's lives? Final report of the independent evaluation of the headspace program. Sydney: Social Policy Research Centre, University of New South Wales, 2015. https://www.headspace.org.au/ assets/Uploads/Evaluation-of-headspace-program.pdf (accessed Sep 2017).

72 Howe D, Coates D, Batchelor S. Headspace Gosford data: the local application of a national model. Australas Psychiatry 2014; 22: 374-377.

73 McCann TV, Lubman DI. Young people with depression and their experience accessing an enhanced primary care service for youth with emerging mental health problems: a qualitative study. BMC Psychiatry 2012: 12: 96.

74 Medlow S, Kelk N, Cohen A, et al. Facilitating early intervention: experiences of young people and implications for the shaping of headspace services. Australas Psychiatry 2010; 18: 335-339.

75 Muir K, McDermott S, Gendera S, et al. Independent evaluation of headspace: the National Youth Mental Health Foundation: interim evaluation report. Sydney: Social Policy Research Centre, University of New South Wales, 2009. https://www.sprc.unsw.edu.au/media/ SPRCFile/2009_Report5_09_headspace_interim evalreport.pdf (accessed Sep 2017)

76 Muir K, Powell A, McDermott S. 'They don't treat you like a virus': youth-friendly lessons from the Australian national youth mental health foundation. Health Soc Care Community 2012; 20: 181-189.

77 O'Dea B, Glozier N, Purcell R, et al. A cross-sectional exploration of the clinical characteristics of disengaged (NEET) young people in primary mental healthcare. BM Open 2014; 4: e006378.

78 O'Dea B, Lee RS, McGorry PD, et al. A prospective cohort study of depression course, functional disability, and NEET status in help-seeking young adults. Soc Psychiatry Psychiatr Epidemiol 2016; 51: 1395-1404.

79 Purcell R, Jorm AF, Hickie IB, et al. Demographic and clinical characteristics of young people seeking help at youth mental health services: baseline findings of the Transitions Study. Early Interv Psychiatry 2015; 9: 487-497.

80 Rickwood D, Anile G, Telford N, et al. Service Innovation Project Component 1: best practice framework Melbourne: headspace, National Youth Mental Health 
Foundation, 2014. https://headspace.org.au/assets/ Uploads/Corporate/Publications-and-research/ headspace-best-practice-framework-april-2014.pdf (accessed Sep 2017)

81 Rickwood D, Nicholas A, Mazzer K, et al. Satisfaction with youth mental health services: further scale development and findings from headspace - Australia's National Youth Mental Health Foundation. Early Interv Psychiatry 2017; 11: 296-305.

82 Rickwood D, Telford N, Mazzer K, et al. Service Innovation Project Component 2: social inclusion model development study. Melbourne: headspace, National Youth Mental Health Foundation, 2015. https:// www.headspace.org.au/assets/Uploads/Corporate/ Publications-and-research/HSP201-Service-InnovationPart-2-FA-LR.pdf (accessed Sep 2017).

83 Rickwood D, Van Dyke N, Telford N. Innovation in youth mental health services in Australia: common characteristics across the first headspace centres. Early Interv Psychiatry 2015; 9: 29-37.

84 Rickwood DJ, Mazzer KR, Telford NR, et al. Changes in psychological distress and psychosocial functioning in young people visiting headspace centres for mental health problems. Med J Aust 2015; 202: 537-542. https:// www.mja.com.au/journal/2015/202/10/changespsychological-distress-and-psychosocial-functioningyoung-people

85 Rickwood DJ, Telford NR, Mazzer KR, et al. The services provided to young people through the headspace centres across Australia. Med J Aust 2015; 202: 533-536. https:// www.mja.com.au/journal/2015/202/10/servicesprovided-young-people-through-headspace-centresacross-australia

86 Rickwood DJ, Telford NR, Parker AG, et al. headspace - Australia's innovation in youth mental health: who are the clients and why are they presenting? Med J Aust 2014; 200: 108-111. https://www.mja.com.au/ journal/2014/200/2/headspace-australias-innovationyouth-mental-health-who-are-clients-and-why-are

87 Scott EM, Hermens DF, Glozier N, et al. Targeted primary care-based mental health services for young Australians. Med J Aust 2012; 196: 136-140. https://www.mja.com. au/journal/2012/196/2/targeted-primary-care-basedmental-health-services-young-australians

88 Scott EM, Hermens DF, Naismith SL, et al. Thoughts of death or suicidal ideation are common in young people aged 12 to 30 years presenting for mental health care. BMC Psychiatry 2012; 12: 234

89 Watsford C, Rickwood D. Young people's expectations, preferences and actual experience of youth mental health care. Int J Adolesc Youth 2015; 20: 284-294.

90 Simmons MB, Parker AG, Hetrick SE, et al. Development of a satisfaction scale for young people attending youth mental health services. Early Interv Psychiatry 2014; 8: 382-386.

91 Patulny R, Muir K, Powell A, et al. Are we reaching them yet? Service access patterns among attendees at the headspace youth mental health initiative. Child Adolesc Ment Health 2013; 18: 95-102.

92 Amara F, Naves P. [Evaluation de la mise en place du dispositif "maison des adolescents" (MDA): rapport ] [French]. Paris: Membres de l'Inspection Generale des Affaires Sociales, 2013

93 lyer SN, Boksa P, Lal S, et al. Transforming youth mental health: a Canadian perspective. Ir J Psychol Med 2015; 32: 51-60.

94 National Health and Medical Research Council. NHMRC additional levels of evidence and grades for recommendations for developers of guidelines. Canberra: NHMRC, 2009. https://www.nhmrc.gov.au/_files_nhmrc/ file/guidelines/developers/nhmrc_levels_grades_ evidence_120423.pdf (accessed Sep 2017).
95 Nicholas J. The role of internet technology and social branding in improving the mental health and wellbeing of young people. Perspect Public Health 2010; 130: 86-90.

96 Liebenberg L, Sanders J, Munford R. A positive youth development measure of service use satisfaction for youth: the 13-item youth services satisfaction (YSS-13). Child Youth Serv Rev 2016; 71: 84-92.

97 Gopalan G, Lee SJ, Harris R, et al. Utilization of peers in services for youth with emotional and behavioral challenges: a scoping review. J Adolesc 2017; 55: 88-115.

98 Simmons MB, Batchelor S, Dimopoulos-Bick T, et al. The Choice Project: peer workers promoting shared decision making at a youth mental health service. Psychiatr Serv 2017; 68: 764-770

99 Rochford T. Whare Tapa Wha: a Mäori model of a unified theory of health. J Prim Prev 2004; 25: 41-57.

100 Durie MH. A Maori perspective of health. Soc Sci Med 1985; 20: 483-486.

101 Australian Government Department of Health. Primary Health Networks: grant programme guidelines. Canberra: Department of Health, Feb 2016. http://www. health.gov.au/internet/main/publishing.nsf/content/ PHN-Program_Guidelines (accessed Sep 2017).

102 Denny S, Farrant B, Utter J, et al. The prevalence of postgraduate education in youth health among high school clinicians and associated student health outcomes. J Adolesc Health 2016; 59: 555-561.

103 Settipani CA, Cleverley K, Hawke LD, et al. Essential components of integrated care for youth with mental health and addiction needs: protocol for a scoping review. BMJ Open 2017; 7: e015454.

104 Gehring ND, McGrath P, Wozney L, et al. Pediatric eMental healthcare technologies: a systematic review of implementation foci in research studies, and government and organizational documents. Implement Sci 2017; 12: 76 . 